\title{
Unusual pulmonary metastatic pattern in a case of pancreatic cancer
}

\author{
Nirav Shah, ${ }^{1}$ Akeel Jubber, ${ }^{2}$ Marcin Osman, ${ }^{1}$ Imran Syed ${ }^{3}$ \\ ${ }^{1}$ Department of Respiratory Medicine, King George Hospital, Essex, UK; \\ 2Department of Respiratory Medicine, Queen's Hospital, Essex, UK; \\ ${ }^{3}$ Radiology Department, Queen's Hospital, Essex, UK \\ Correspondence to Dr Nirav Shah, N1R4V@yahoo.com
}

\section{Summary}

The authors report the case of a cystic pancreatic cancer with pulmonary metastasis to illustrate the unusual radiographic halo-sign appearance of nodular/consolidative change with surrounding ground glass pattern and also to highlight the histopathological background underlying this pattern.

\section{BACKGROUND}

Pancreatic cancer is the fourth leading cause of cancer deaths among men and women, comprising $6 \%$ of all cancer-related deaths with a lifetime risk of about 1 in 72 $(1.38 \%)$. The diagnosis of pancreatic cancer is extremely difficult to establish in its early stages such that at the time of diagnosis, about $52 \%$ have distant metastatic disease. However, although pulmonary metastatic deposits are often identified on cross-sectional imaging, rarely do they cause symptoms that lead to the clinical presentation.

\section{CASE PRESENTATION}

A 70-year-old man presented as an outpatient with a 6-month history of cough productive of creamy white sputum but no haemoptysis. During this time he had received three courses of antibiotics with no significant improvement in his symptoms. He denied any systemic symptoms and in particular he did not have any weight loss, anorexia or change in bowel habit. He had a 45-pack/year history of smoking with previous occupational asbestos exposure in the 1960's as both a pipe-fitter and dockyard worker. His medical history included hyperlipidaemia, benign prostatic hypertrophy with previous trans-urethral resection of the prostate.

\section{INVESTIGATIONS}

Physical examination was only notable for occasional basal crackles. Chest x-ray revealed bilateral rounded heterogenous consolidative lesions. A CT scan was performed and this showed multiple, bilateral, mainly angio-centric consolidative lesions some with air bronchograms, varying in size which coalescence to form larger areas of focal ground glass opacities, particularly within the lower zones where the opacities were more widespread. The appearances are extremely unusual for intrapulmonary metastatic disease and have not been widely reported before. The circumferential peripheral ground glass change to the more central consolidative nodules is illustrated (figure 1). The CT scan incidentally disclosed a small pancreatic cyst in the pancreatic head.
Sputum microscopy and culture yielded moderate growth of normal upper respiratory tract flora with no acid fast bacilli, yeasts or aspergillus. Sputum cytology showed alveolar macrophages with no abnormal or malignant cells. The patient's peripheral blood film and differential counts were normal and his inflammatory markers were within normal limits. Serum aspergillus precipitins were negative. He was investigated for possibility of a vasculitic or granulomatous process and was found to have negative IgG anti-neutrophil cytoplasmic antibodies and antinuclear antibody, serum ACE of $67.0 \mathrm{iu} / 1$ (15-70) and total IgE 29.4 kU/1 (0-81). Serum tumour markers revealed prostate specific antigen (PSA) of $4.8 \mathrm{ug} / 1$ (0-4), carcinoembryonic antigen (CEA) $2.3 \mathrm{ug} / 1$ (0-4) and cancer antigen (CA) 19-9 $19 \mathrm{kU} / 1$ (0-33). A fibre-optic bronchoscopy revealed normal appearances of the endobronchial tree with no lesions seen and broncho-alveolar lavage from the right lower lobe yielded normal bronchial epithelial cells, alveolar macrophages and no malignant cells. Culture of these specimens yielded a moderate growth of normal upper respiratory tract flora.

An endoscopic ultrasound-guided aspiration of the pancreatic cyst revealed fluid CEA 293 ug/l. Simultaneous biopsy showed a background of blood with numerous foamy macrophages, consistent with a cyst, there were moderate numbers of variably sized epithelial cell groups sometimes showing vacuolated cytoplasm with the smaller rounded groups representing normal exocrine pancreatic acini occasionally surrounded by mucin; in some larger groups, cell nuclei had enlarged and had pleomorphic appearance with distinct single nucleolus. The overall histological picture was in keeping with a mucinous cystic neoplasm with mildly atypical cytological features. The reporting histopathologist commented that such tumours have a spectrum of behaviour from benign to malignant and with the mildly atypical cytological features clinical correlation was required.

CT guided biopsy of a peripheral lung lesion revealed fragments of lung tissue largely replaced by a well-differentiated adenocarcinoma with a lepidic growth pattern. 


\section{BMJ Case Reports}

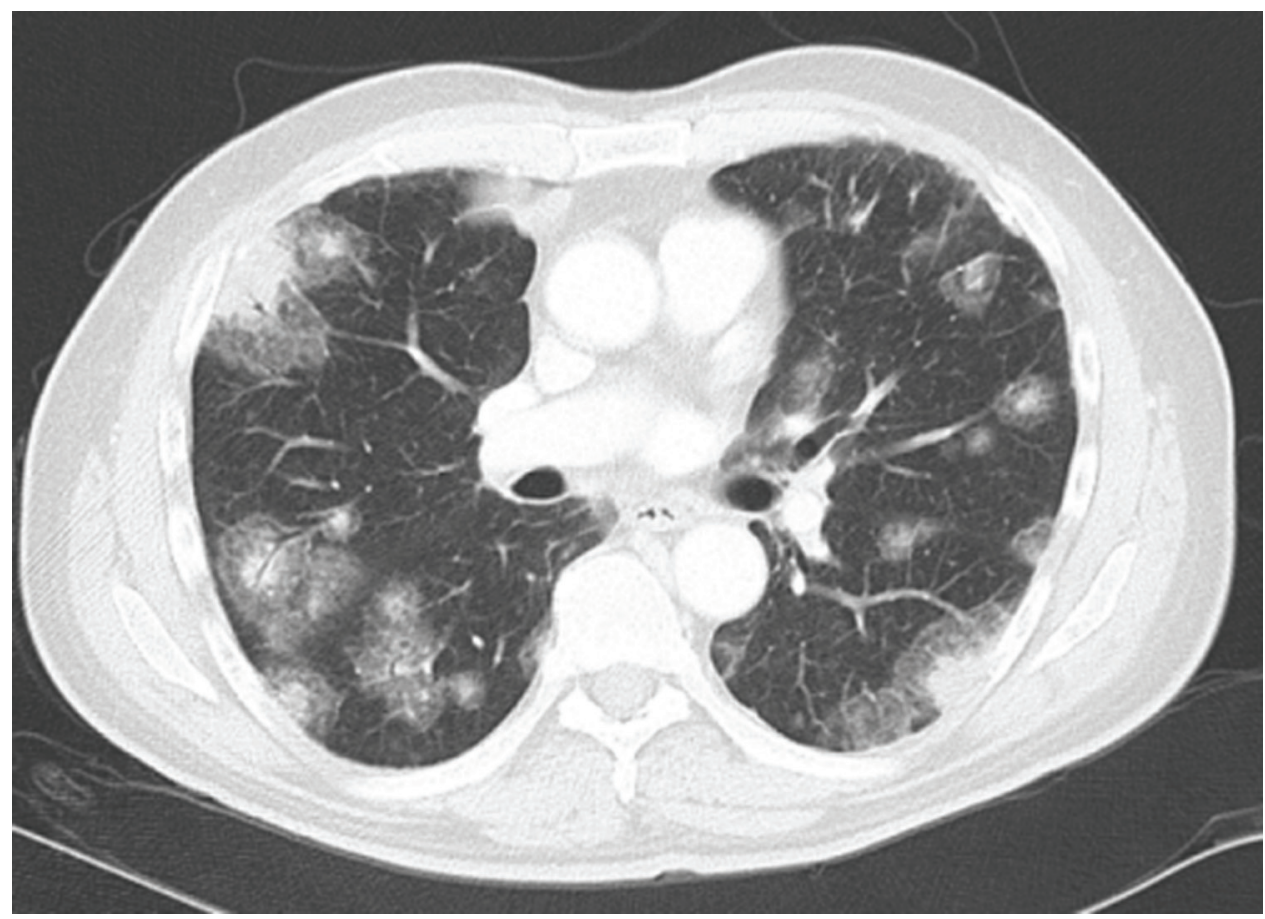

Figure 1 Thoracic CT at first presentation.

Immunohistochemistry demonstrated that the tumour cells were positive with cytokeratin 7 (CK7), but not CK20, thyroid transcription factor-1, CDX-2, PSA or CD99. eGFR mutations were not detected. There was focal expression of CA19-9. This profile was suggestive of metastasis from the pancreatic mucinous cystic neoplasm.

\section{OUTCOME AND FOLLOW-UP}

The patient was given palliative single agent gemcitabine chemotherapy but unfortunately died 8 weeks later.

\section{DISCUSSION}

The differential diagnosis of multiple pulmonary nodules is wide and includes malignancy, abscesses, septic emboli, fungal infection and parasitic infestation such as paragonimiasis, arterio-venous malformations and pneumoconioses in addition to lung nodules of inflammatory or granulomatous aetiology associated with conditions such as Wegener's granulomatosis, rheumatoid arthritis and sarcoidosis. Such nodules may also develop as a result of primarily non-malignant extra-thoracic disease such as pulmonary endometriosis and also the sequelae of iatrogenic injury. ${ }^{1}$

Typical radiographic findings of a pulmonary metastasis include multiple peripherally located round variable-sized nodules in the case of haematogenous metastasis and diffuse thickening of the interstitium with lymphangitic spread. $^{2}$ In patients with a known malignancy, multiple pulmonary nodules that are greater than $1 \mathrm{~cm}$ are most commonly due to metastatic solid organ malignancy. Malignant lung nodules are usually round with well demarcated borders, exceptions include haemorraghic metastases from choriocarcinoma, renal cell carcinoma, melanoma and thyroid malignancy where borders tend be less distinct and may have a surrounding halo. ${ }^{3}$ The halo-sign is a term applied to the ground glass attenuation surrounding a pulmonary nodule and is not always indicative of metastatic spread. The change in the density of the metastatic deposit from the centre to the periphery is believed to represent grades of tumour differentiation and mucin secretion.

In practice, atypical pulmonary metastases can be encountered and knowledge of their radiological appearances and histological patterns is useful to facilitate early diagnosis. These atypical radiological findings of pulmonary metastases have been categorised into several patterns, with the lepidic growth pattern, observed in our case, also being acknowledged. ${ }^{2}$ The lepidic growth pattern, or air-space shadowing, has been described in cases of pulmonary metastasis secondary to gastrointestinal malignancy. This pattern is quite similar to that of mucinous bronchioloalveolar carcinoma (BAC) and differentiation between BAC and pulmonary metastasis with a lepidic growth pattern on histological basis is extremely difficult. In an autopsy study by Rosenblatt et al, the lepidic growth pattern associated with pulmonary metastasis was found in $66 \%$ of small intestinal cancer, $27 \%$ of pancreatic cancer and $15 \%$ of colonic cancer. ${ }^{4}$ There is good evidence to show that histological features do to some extent determine the radiographic pattern due to the abundance of mucin in the glandular neoplastic cells along the alveolar wall. ${ }^{5}$ It is worth noting that the lepidic growth pattern may lead to a number of radiological appearances such as air-space nodules, parenchymal consolidation, focal or extensive ground glass opacity and nodules with a halo sign. ${ }^{5} 6$ 


\section{BMJ Case Reports}

\section{Learning points}

- The differential diagnosis of multiple pulmonary nodules is wide

- Malignant lung nodules are usually round with well demarcated borders

- Knowledge of histological patterns and radiological appearances of atypical pulmonary metastases is useful to facilitate early diagnosis

- The 'halo-sign' term can be applied to a histological lepidic growth pattern with radiological evidence of central consolidative change and peripheral ground glass pattern.
Patient consent Obtained.

\section{REFERENCES}

1. Lee YR, Choi YW, Lee KJ, et al. CT halo sign: the spectrum of pulmonary diseases. Br J Radiol 2005;78:862-5.

2. Seo JB, Im JG, Goo JM, et al. Atypical pulmonary metastases: spectrum of radiologic findings. Radiographics 2001;21:403-17.

3. Ginsberg MS, Griff SK, Go BD, et al. Pulmonary nodules resected at video-assisted thoracoscopic surgery: etiology in 426 patients. Radiology 1999;213:277-82.

4. Rosenblatt MB, Lisa JR, Collier F. Primary and metastatic bronciolo-alveolar carcinoma. Dis Chest 1967; 52:147-52.

5. Okafujia T, Sakaia S, Yoshimitsua K, et al. Pulmonary metastasis from pancreatic cancer: a case showing biphasic radiological and histological patterns. CMIG Extra: Cases 2004;28:68-71.

6. Gaeta $\mathbf{M}$, Volta $\mathrm{S}$, Scribano $\mathrm{E}$, et al. Air-space pattern in lung metastasis from adenocarcinoma of the Gl tract. J Comput Assist Tomogr 1996;20:300-4.

Competing interests None.

This pdf has been created automatically from the final edited text and images.

Copyright 2011 BMJ Publishing Group. All rights reserved. For permission to reuse any of this content visit http://group.bmj.com/group/rights-licensing/permissions.

BMJ Case Report Fellows may re-use this article for personal use and teaching without any further permission.

Please cite this article as follows (you will need to access the article online to obtain the date of publication).

Shah N, Jubber A, Osman M, Syed I. Unusual pulmonary metastatic pattern in a case of pancreatic cancer. BMJ Case Reports 2011; 10.1136/bcr.06.2011.4365, date of publication

Become a Fellow of BMJ Case Reports today and you can:

- Submit as many cases as you like

- Enjoy fast sympathetic peer review and rapid publication of accepted articles

- Access all the published articles

- Re-use any of the published material for personal use and teaching without further permission

For information on Institutional Fellowships contact consortiasales@bmjgroup.com

Visit casereports.bmj.com for more articles like this and to become a Fellow 